University of Nebraska - Lincoln

DigitalCommons@University of Nebraska - Lincoln

Faculty Publications in Educational

Administration

Educational Administration, Department of

2020

Narratives of queer men of color in culturally-based fraternities

making meaning of masculinities

Antonio Duran

Crystal Garcia

Follow this and additional works at: https://digitalcommons.unl.edu/cehsedadfacpub

Part of the Educational Administration and Supervision Commons

This Article is brought to you for free and open access by the Educational Administration, Department of at DigitalCommons@University of Nebraska - Lincoln. It has been accepted for inclusion in Faculty Publications in Educational Administration by an authorized administrator of DigitalCommons@University of Nebraska - Lincoln. 


\title{
Narratives of queer men of color in culturally-based fraternities making meaning of masculinities
}

\author{
Antonio Duran ${ }^{1}$ and Crystal E. Garcia² \\ 1 Auburn University, Auburn, AL, USA \\ 2 University of Nebraska-Lincoln, Lincoln, NE, USA \\ Correspondence - Antonio Duran aad0051@auburn.edu ; Haley Center 4082, \\ Auburn University, Auburn, AL, 36849, USA
}

ORCID Antonio Duran https://orcid.org/0000-0002-3990-6796

\begin{abstract}
This constructivist grounded theory study examined how Queer Men of Color in culturally-based fraternities made meaning of their masculinities. Through two intensive interviews and a reflection journal activity, nine participants shared their constructions of masculinities before joining a culturally-based organization and how their thinking changed after affiliating with a fraternity. Specifically, Queer Men of Color first spoke to pre-collegiate experiences that largely shaped their views of masculinities. Next, participants discussed how culturally-based fraternities both reinforced hegemonic masculinity, as well as opened up the possibilities to construct a more productive view of masculinities. Implications are then offered for chapter advisors, fraternity and sorority life, and national organizations.
\end{abstract}

Keywords: Queer, men of color, masculinities, fraternities, meaning making

Within the past decade, scholars contributed to the literature on their masculinities (e.g. Dancy, 2011; Edwards \& Jones, 2009; Foste

Published in International Journal of Qualitative Studies in Education 2020, 17 pp; doi:10.1080/09518398.2020.1828652

Copyright (c) 2020 Informa UK Limited, trading as Taylor \& Francis Group. Used by permission.

Submitted 21 October 2019; accepted 22 September 2020; published 8 October 2020. 
\& Davis, 2018; Harris, 2010; Tillapaugh, 2013, 2015a, 2015b), though oftentimes centered those who identified as cisgender. This research portrayed masculinities in pluralistic ways (Catalano, Wagner, \& Davis, 2018), interrogating the positive and negative manifestations of this complex construct (Connell, 1995). Yet, as Tillapaugh (2015b) wrote in relation to intersectionality and gay college men, 'the aggregation of 'men' as a collective reinforces heteronormative and patriarchal views on men and masculinity' (p. 173). Answering this call to comprehend the differences that exist, scholarship also identified how masculinities differ for college men who identify as queer (Chan, 2017; Strayhorn \& Tillman-Kelly, 2013; Tillapaugh, 2015a).

Of note, researchers explained how collegiate environments influence queer men's meaning making of their masculinities. Meaning making, a constructivist-developmental concept, describes how people come to know and understand the world around them (Kegan, 1994; Baxter Magolda, 2009). Specifically, fraternal cultures emerged as spaces where queer men navigate hegemonic masculinity and homophobia (DeSantis \& Coleman, 2008; Yeung, Stombler, \& Wharton, 2006) that in turn can shape their meaning making. Still, these studies run the risk of homogenizing queer men's experiences in fraternal organizations. Notably, researchers failed to question how race can play a role in queer men's masculinities, especially in culturally-based fraternities. Culturally-based organizations include: historically Black fraternities within the National Panhellenic Council (NPHC), as well as Asian American, Latino, Native American, and multicultural-based organizations typically grouped within campus Multicultural Greek Councils (MGC). Culturally-based fraternities share many of the same characteristics of historically white fraternities such as organizational symbols, rituals, and values. However, they are also distinct in many ways; notably, because they were founded in response to racial discrimination (Torbenson, 2009), these organizations center Communities of Color. Still, even though culturally-based fraternities have the potential to affirm collegians' racial identities, questions remain of how these spaces contribute to Queer Men of Color's masculinities.

Thus, considering the unique context of culturally-based fraternal organizations as gendered and racialized spaces, the purpose of this constructivist grounded theory (Charmaz, 2014) was to investigate how Queer Men of Color in culturally-based fraternities made 
meaning of their masculinities. In particular, we drew upon scholarship pertaining to the social construction of gender, together with research on meaning making (e.g. Baxter Magolda, 2009; Kegan, 1994). The research question that guided this project was as follows: How do Queer Men of Color make meaning of their masculinities before and after they join a culturally-based fraternity? Because this project examined participants' experiences before, during, and after college, this study contributes to the body of knowledge on college fraternities, especially due its focus on Queer Men of Color within them.

\section{Literature review}

To set the foundation for the study, we surveyed literature relevant to the process of interest: the meaning making of masculinities. Sensitizing bodies of research for this project included literature on college men's masculinities and meaning making, as well as masculinities in culturally-based fraternities.

\section{College men's masculinities and meaning making}

Research on college men's masculinities grew due to an interest in systems of patriarchy and misogyny structuring individuals' lives (Catalano et al., 2018), though oftentimes focused on cisgender individuals. Catalano et al. (2018) defined masculinities as a 'particular form of gender expression, style, performance, and organizational process that coalesces with other factors (e.g. economic systems) that generally support and construct patriarchy' (p. 12). Yet, the study of masculinities has acknowledged several forms this concept can take with scholars emphasizing how college men construct conceptualizations that are hegemonic, inclusive, or productive. Hegemonic masculinities are described as an ideology where men establish dominance over other genders through exaggerated actions like aggression or hypersexuality (see Connell, 1987). Additionally, hegemonic masculinities manifest in the ways that men themselves idolize these particular forms of masculinity, which marginalizes those who do not align with these attitudes and behaviors. Inclusive masculinities refer to 'the social inclusion of those traditionally marginalized by hegemonic masculinity' 
(Anderson, 2008, p. 606). Finally, productive masculinities are 'healthy' or 'well-rounded' masculinities that 'have been linked...to a host of desirable...outcomes' (Harris \& Harper, 2014, p. 706).

Within this scholarship, researchers examined the contexts, including pre-college and higher education settings, informing college men's masculinities (e.g. Chan, 2017; Harris \& Harper, 2015; Tillapaugh, 2013). For example, Harris and Harper (2015) study on sixty-eight men highlighted the role of parents, peer interactions, and engagement with youth athletics. As a result of these influences, participants came to higher education inculcated in beliefs around providing for others, emphasizing masculine pursuits (e.g. heterosexual behaviors), and displaying a great deal of confidence. Additionally, Tillapaugh (2013) underscored how gay men enter higher education with similar ideas garnered by family and friends. However, a key difference was that gay men performed hegemonic masculinity while downplaying or not disclosing their sexuality. Likewise, Chan (2017) shared how faith in the Filipino culture reinforced notions of masculinities and heteronormativity-an ideology in which heterosexuality is posited as the norm-for gay Filipino men growing up.

Surveying the literature also has revealed the differential impacts that college can have on students' constructions of masculinities (Dancy, 2011; Edwards \& Jones, 2009; Foste \& Davis, 2018; Harris, 2010; Tillapaugh, 2013, 2015a, 2015b). Research has shown that college is a place where men's notions of masculinities are typically challenged, while also serving as a site where hegemonic masculinity is replicated. Specifically, Harris (2010) discussed how aspects of the collegiate environment like academic interests, male peer group interactions, and campus involvement inform masculinities. As it pertains to cisgender Men of Color, scholars communicated that these individuals use experiences in college to contest perceptions of their masculinities. For example, literature on Black men communicated that these students succeed academically and in extracurricular activities, hoping to challenge racial and gendered stereotypes (Dancy, 2011).

In addition to investigating the role of contextual influences, scholars illustrated the relationship between meaning making and masculinities (e.g. Edwards \& Jones, 2009; Foste \& Davis, 2018; Hughes, 2017; Tillapaugh, 2013, 2015a). One example was Edwards and Jones 
(2009) study on ten college men arguing that these individuals progressed from an externally defined conceptualization of manhood, frequently characterized by hegemonic behaviors, toward an internal construction of masculinity. Though not the central focus of their research, Edwards and Jones (2009) stated that these findings suggested a development in students' meaning-making capacities. Especially relevant to this present study, Tillapaugh (2015a) examined meaning making with a population of sexual minority men. Tillapaugh contended that having access to spaces which actively interrogated heteronormative and hegemonic influences, such as LBGT-affirming environments or student leadership involvement, allowed gay men to see sexuality and gender from a more internal meaning-making structure. Beyond the contexts noted above, scholars also studied how culturally-based fraternities perpetuate different views on masculinities (e.g. Anderson, Buckley, \& Tindall, 2011; DeSantis \& Coleman, 2008; Jenkins, 2012; Mahoney, 2019; McGuire, McTier, Ikegwuonu, Sweet, \& Bryant-Scott, 2020).

\section{Culturally-based fraternities and masculinities}

Though research exists about hegemony masculinity in fraternity life broadly (see Biddix, 2016 for a review of the literature), as well as the productive masculinities that also manifest (Anderson, 2008; Harris \& Harper, 2014), it was important to survey the scholarship specific to culturally-based fraternal organizations. Namely, a subset of scholars has studied masculinities in the context of culturally-based fraternities (e.g. Anderson et al., 2011; DeSantis \& Coleman, 2008; Jenkins, 2012; Mahoney, 2019; McGuire et al., 2020). This scholarship has articulated how Men of Color construct masculinities with gender and race in mind. Jenkins (2012) provided one perspective stating that members in Black fraternal organizations reproduced stereotypes pertaining to Black manhood, including heteronormativity, through their initiation processes. Conversely, other scholars argued that culturally-based fraternities have positive outcomes on masculinities. As McGuire et al. (2020) noted in their study on Black Christian fraternity men, organizations can be spaces where they engage in intimacy, embodying 'forms of raced-gendered masculinities traditionally policed and critiqued in larger homosocial environments' 
(p. 13). Though work on culturally-based fraternities largely centers Black men, this scholarship contextualizes the influence of organizations for Queer Men of Color broadly.

Still, only a few scholars have focused on the impact of culturallybased organizations on gay members (see DeSantis \& Coleman, 2008; Mahoney, 2019; Williams, 2017). For example, DeSantis and Coleman (2008) noted that Black fraternity men perpetuated certain maxims, which included a belief in being strong, hypersexual, and avoiding embodying white culture by being too refined or intellectual. Participants in their study referenced not wanting gay individuals in the organization, perceiving that the stereotypes associated with queer men did not fit with the qualities they revered. In Williams (2017) research on Black gay men in historically Black Greek letter fraternities, he found that gay men who fit traditional notions of masculinity were less likely to be targeted even though they still reported instances of heterosexism and homophobia. Potentially explaining why these behaviors exist within Black fraternal spaces, Mahoney (2019) argued that the institutionalization of minority differences within higher education in the post-Civil Rights era led to a conceptualization of racial uplift that privileged cis-heteropatriarchy. Therefore, it is important not to see these behaviors as problems originating within Communities of Color, but rather those that are always emerging in response to whiteness. Though limited, this scholarship set a foundation for the present research's interest in how Queer Men of Color make meaning of masculinities in culturally-based fraternities.

\section{Conceptual framework}

To guide the present research, we drew on bodies of scholarship concerning the social construction of gender, especially the ways that hegemonic masculinities functions within such systems, as well as meaning making. First, we entered into this project recognizing that gender is a product of larger societal ideologies that regulates matters of expression, performance, and identity (Connell, 1995; Kimmel \& Messner, 2013). Put simply, gender is not biologically determined, but is instead constituted by society. In this system, hegemonic masculinity, a dominant ideology that positions men in power (Connell, 1987), 
serves to privilege certain behaviors that inherently disenfranchises other genders and those who do not fit within this conceptualization of masculinities (e.g. queer bodies). Vital to underscore is that gender as a social construction means that multiple forms of masculinities exist and are influenced by certain contexts or cultures (Connell, 1995; Kimmel \& Messner, 2013). Therefore, it is crucial to see gender as a construct that is also shaped by matters of race, for instance.

Recognizing gender as a social construction, we also were informed by scholarship on meaning making (Kegan, 1994; Baxter Magolda, 2009). Kegan (1994) asserted that a person's meaning-making structures are predicated on the subject-object relationship, in which object represents that which we can tangibly hold and have control over whereas subject is that which we are not yet able to identify. As people develop, that which is subject becomes object, showcasing a more complex meaning-making structure. Using Kegan (1994) scholarship, Baxter Magolda (2009) longitudinal research showcased how people develop in their meaning-making structures by moving away from relying upon external formulas, before entering a crossroads, and then finally constructing an internal voice. Therefore, this research assisted us in comprehending how Queer Men of Color made meaning of their masculinities, especially as it relates to dominant social constructions surrounding them.

\section{Study design}

This study was guided by constructivist grounded theory as its methodological tradition. Constructivist grounded theory follows an inductive procedure and seeks to develop a theory from the data, explaining how and why a social process occurs (Charmaz, 2014). With a process of interest at the center of the study-the meaning making of masculinities-constructivist grounded theory assisted us with generating a theory that honored the participants' stories and that revealed the role that culturally-based fraternities played in their masculinities. This methodology has numerous defining characteristics that we adhered to in the study design, further explored in the subsequent subsections. 


\section{Participant selection and recruitment}

We first secured IRB approval prior to reaching out to potential participants for this study. To select participants, we engaged in a criterion sampling strategy (Creswell \& Poth, 2018), seeking individuals who fit the following criteria: (1) Identified with the term queer; (2) Identified as a Person of Color; (3) Identified as a man aged 18+; and (4) Is a member of a Multicultural Greek Council (MGC) or National Pan-Hellenic Council (NPHC) fraternal organization. For this project, we searched for those who had already graduated from their undergraduate institution since they could reflect on their experiences more thoroughly as a result of being alumni. We shared the call via Facebook, Instagram, and Twitter. Thirteen individuals submitted their interest to participate. From this pool, we selected nine Queer Men of Color, including six NPHC and three MGC fraternity members, based on their adherence to selection criteria. Participants selected their own pseudonyms. Information about participants' social identities, backgrounds, and fraternal affiliation are included in Table 1. However, we recognize that a limitation of this study is that only Black and Latino men shared an interest in participating, together with the fact that no one identified as trans. We still employ the terminology of 'Queer Men of Color' to honor the language that we used in recruitment while encouraging future research on trans men, as well as those within other culturally-based fraternities including Native- and Asian/Asian American, Pacific Islander, and Desi ${ }^{1}$ American-based organizations. Our participant pool was limited by the nature of the organizational type and focus of the study; therefore, we also recognize that the small participant size is another limitation of this work.

\section{Data collection}

Once participants were selected, they engaged in a variety of data collection opportunities, including the completion of a demographic form, two virtual intensive interviews (Charmaz, 2014) conducted via Zoom that lasted approximately 60-90 minutes (most of which lasted a full 90 minutes), and a reflection journal activity. All interviews were audio recorded and transcribed. Data collection occurred over the course of one academic semester. Following the completion of the first interview, we asked participants to write approximately one page 
Table 1. Profile of queer men of color (self-reported on a demographic form).

\begin{tabular}{lccccc} 
Namea & Pronouns & Race/Ethnicity & $\begin{array}{c}\text { NPHC } \\
\text { or MGC } \\
\text { Organization? }\end{array}$ & $\begin{array}{c}\text { Yearganization } \\
\text { Name }\end{array}$ & $\begin{array}{c}\text { Graduating from } \\
\text { Undergraduate } \\
\text { Institution }\end{array}$ \\
\hline Aaron & He/him & African American & NPHC & Upsilon & 10 Years or More \\
August & $\mathrm{He} / \mathrm{him}$ & Black & NPHC & Omicron & $1-3$ Years \\
Benjamin & $\mathrm{He} / \mathrm{him}$ & Latino & MGC & Phi & $4-6$ Years \\
Derek & $\mathrm{He} / \mathrm{him}$ & Latino & MGC & Phi & $1-3$ Years \\
Evan & $\mathrm{He} / \mathrm{him}$ & African-American & NPHC & Upsilon & 10 Years or More \\
Jeff & $\mathrm{He} / \mathrm{him}$ & Black & NPHC & Upsilon & 10 Years or More \\
Komplexity & $\mathrm{He} / \mathrm{him}$ & African-American & NPHC & Tau & 7-9 Years \\
Scott & $\mathrm{He} / \mathrm{him}$ & Black & NPHC & Omicron & 10 Years or More \\
Valentino & $\mathrm{He} / \mathrm{him}$ & Afro Latinx & MGC & Phi & 7-9 Years \\
\hline
\end{tabular}

a. Pseudonyms used for research participants and their organizations.

of reflection on each of the following prompts: (1) What interactions/ experiences are you now noticing with the members of your fraternity that are influenced by your identity as a Queer Man of Color? (2) Are there past experiences as a Queer Man of Color in your fraternity that you are reflecting on differently now after our discussion?

To stay true to constructivist grounded theory's inductive nature, we developed the second interview protocol after we analyzed the first round of data from the initial interview and the reflection journal. Throughout the study, we asked participants to reflect on questions such as, 'What were your ideas concerning masculinities prior to joining your organization? What informed them?' and 'What are some experiences that you've had in your organization that have informed your constructions of masculinities?' The answers to these questions led to rich data to analyze. Of note, only eight participants elected to complete their second interview. We decided to keep the ninth participant within the study because their first interview provided enough depth to include their data in our analysis, a decision that we reflected on through memos.

\section{Data analysis}

Grounded theory data analysis implores that researchers make 'analytic sense of stories, statements, and observations' (Charmaz, 2014, p. 111). To accomplish this, we adhered to the constant comparative 
method, which involves inductively generating theoretical categories by comparing data to data, narratives to narratives. Specifically, we employed initial, focused, and theoretical coding to analyze the data. To begin, we individually engaged in line-by-line coding of the interview transcripts, as well as the reflection journal. Focused coding was the second step in the analytic process. Focused coding requires grounded theorists to compare their initial codes, trying to decipher which ideas have the most 'analytical power' (Charmaz, 2014, p. 140). While we coded individually, we also wrote memos (another trait of constructivist grounded theory research) in order to assist us with finding the codes that had the most analytical power. After comparing initial and focused codes, we developed theoretical codes using existing concepts relevant to our conceptual framework and sensitizing bodies of literature: masculinities (e.g. hegemonic, productive), meaning making (e.g. external, crossroads, internal), and fraternal culture (e.g. hazing, rituals). Examples of these codes included: masculinity as one dimensional, masculinity as tied to other identities, relying upon external influences on masculinity, noticing hegemonic forms of masculinity within the fraternity, and productive forms of masculinity within the fraternity. Insights from this final step of coding led to the theoretical categories, which explained the how and why pertaining to the process of interest. This last step revealed theoretical saturation of the categories, another characteristic of grounded theory research (Charmaz, 2014). Throughout data analysis, we attended to trustworthiness techniques to ensure the rigor of this research.

\section{Trustworthiness}

A key component of research, trustworthiness is defined as 'the qualitative paradigmatic means by which to assure a study is of high quality' (Jones, Torres, \& Arminio, 2014, p. 35). We addressed trustworthiness in this study through matters of credibility, transferability, dependability, and confirmability (Jones et al., 2014). First, we engaged credibility, or the 'prolonged engagement in the field and the use of others to confirm findings' (Jones et al., 2014, p. 37), through memberchecking. In particular, after all of data analysis concluded, we shared with participant specific themes that emerged from their interviews/ reflection journal paired with excerpts from transcripts/journals. Four 
participants responded confirming that the themes affirmed their perspectives with the other five not responding. Next, transferability acknowledges the goal of qualitative inquiry to generate findings that have significance for readers. Transferability emerged from our use of substantial quotes and descriptions to allow readers to consider how the results relate to other experiences. Finally, we achieved dependability and confirmability-tracking the research procedures and connecting findings to the data itself, respectively-through our use of analytic memos. In these memos, we also considered how our positionalities informed the project.

\section{Researcher positionality}

In order to honor constructivist grounded theory's attention to how researchers inherently shape the inquiry process (Charmaz, 2014), we offer positionality statements that capture our reflexive memos and conversations with one another. Antonio Duran (he/him) identifies as a queer Latino cisgender man. Though Antonio is not affiliated with a fraternity, his research interests include examining the realities of Queer People of Color in communities that only center one marginalized identity. Throughout this project, Antonio found himself writing about how he consistently internalized hegemonic masculinity growing up, leading to feelings of disdain toward his sexuality. Antonio consequently considered how participants experienced similar sentiments prior to college and in culturally-based fraternities.

Crystal Garcia (she/her) identifies as a multiracial Latina and White, heterosexual cisgender woman. She is a member of a Panhellenic Sorority, served as a chapter advisor for her sorority for several years, and worked closely with the fraternity and sorority life (FSL) community during her time as a student affairs professional. Although she was not a member of a culturally-based sorority, much of her research centers on students' experiences within these organizations. Because Crystal does not identify as a Queer Man of Color, she continuously questioned ways she interpreted participants' experiences and discussed these perceptions with Antonio. She acknowledged that when people meet her, they assess her physical appearance and almost always assume she is a white person and erase her Latina identity. Because she is white passing, she has never experienced overt racial discrimination 
or hostilities from strangers based on her physical presence, which she realized was distinct from many of the participants' experiences. She also reflected on how her positionality played a role in this work as her previous experiences within FSL exposed her to ways hypermasculinity and heteronormativity perpetuated in fraternal organizations. She recognized these perspectives and often debriefed with the first author to ensure these did not influence her understanding of participants' experiences.

\section{Findings}

Findings revealed how Queer Men of Color made meaning of masculinities during three distinct periods in their life: pre-collegiate experiences, time in their undergraduate chapter, and post-college interactions with the organization. Queer Men of Color discussed how prior to college, they largely learned ideals of masculinities from families and peers. These ideas were both replicated and challenged within their culturally-based fraternity. Participants shared how their constructions of masculinities were first externally defined before then moving toward a more internal view of masculinities.

\section{Pre-college: family and peers as a key influence of meaning making}

Prior to attending their undergraduate institutions and joining their fraternal organizations, Queer Men of Color described their meaning making about their masculinities as externally defined by influences such as family, community, and school settings. These contexts taught individuals that masculinities were constructed on normalized gendered roles and heteronormative beliefs. To communicate this idea, August shared,

Prior to joining my organization [Omicron], my conceptualization of masculinity was, um, it was very ... I'll say until around the time that I joined, it had one look. It had one version. It was very flat .... And also, this could be a part of the environment that I came from, but it was very ... straight. 
August explained that his understanding of masculinities was drawn from the boys and men he grew up around: 'They all looked the same. They all acted the same .... that look and that image is what I saw for 17 years.' As for the Black men that were part of his life, August felt they were very similar across the board. And so that was the perceived notion that that's what I should be-that's the kind of man.' August then went on to share some constructions that he thought of concerning this one-dimensional nature including 'need[ing] to take care of the household', 'know[ing] how to jump cars,' and 'support[ing] women.' Similar to August, all but one participant identified being a provider or head of the household as part of their construction of masculinities prior to college. For instance, Evan thought, 'A man was to be married, have children. He was to work. He was to be a provider.' In addition, participants described their understanding of masculinities as being strong and 'exerting power' as Komplexity described, or as Valentino and Derek explained, men should not do 'girly things.' Additionally, individuals discussed how this singular definition of masculinities related to cultural values tied to their race/ethnicity.

First, one main influence that shaped their early constructions of masculinities involved their immediate and extended family. Aaron observed how by the time that he was a late adolescent, he only 'knew what was masculine and feminine and that's it.' When asked about what contributed to this binary representation of gender, Aaron described,

I mean, definitely family. I mean, you know, my mom was a teacher. My father was an attorney and in growing up, you know, both parents were there but I spent more time with my mom. And my dad, you know, was the provider, you know, in a sense.

For Aaron, his family fit in the gendered roles that he came to adopt himself. In contrast to Aaron's experience, Scott described how his family rejected traditional gender roles with his mother being more stern than his father. Even though Scott saw an inversion of gender roles in his immediate family, his larger family still reinforced hegemonic ideals: 'As a Black man you carry the weight of the world on 
your shoulders, your family depends on you. And so you cannot show an ounce of weakness.' Compounding on these expectations for Black men, Scott learned at a young age:

Being a Black man and being gay is like a sin worse than anything .... I remember hearing that from very early on that 'we don't raise no fags in this family.' And so that put in in my mindset that as a Black man, I have to be anything but gay. I could be a drug dealer. I could be a gang member. I could be anything but gay. And part of my narrative that I tell people when I tried to help, especially Black people relate to this or understand this. Before I was called a nigger by somebody that was White, I was called a fag by somebody Black.

These messages were difficult for Scott to make sense of which led to him 'struggling ... early on when [he] would hear this is what a Black man should be.' In these examples, Scott referenced the expectations that not only comes with being a man, but ultimately, what it means to be a Black man.

Similarly, other Queer Men of Color shared how they would receive messages tied to heteronormative expectations that informed how they thought about their masculinities. Valentino commented on how family pressures to engage in relationships with women led to him doing so before college: 'I would always get questions from my family, particularly [who live in another country] of: do I have a girlfriend yet?' In response to these constant questions, Valentino performed in ways deemed acceptable by family, especially as it relates to heteronormative ideals: 'And I actually did have girlfriends growing up. So I had a girlfriend when I was in high school.' However, Valentino could not tease out the extent to which his ethnic background influenced his family's expectations around masculinity. He described, 'Whether it's religion, whether it's them being Latino, or whether it's just homophobia in general.' Valentino's reflection underscored the complexity of influences surrounding ways the men came to understand familial expectations around masculinities.

Evident from these examples, familial expectations ingrained conceptualizations of masculinities in these Queer Men of Color. Familial expectations about masculinities oftentimes intricately connected to 
their faith background. One example of this could be seen in Komplexity's narrative as he recalled an experience at his church. As Komplexity mentioned, 'I was a sissy. I was the sweet boy, because I wasn't as masculine or, you know, having experiences-sexual experiences with females etc. Which even in the church was pushed to me.' As a younger Black man, Komplexity was read as not embodying traditional masculine qualities such as being strong or having sex with women, which he reflects on as connected to his identity as a Queer Man of Color. Komplexity then shared a specific instance where he invited a boyfriend to church only to have his godfather confront him about 'the faggot you brought to church.' This experience represented one manner in which family enforced a singular type of masculinities using faith. As a result of these influences, Komplexity still internalized that his identities, as someone more feminine and queer, was inherently a problem: 'So it was a lot of internal... struggle because I couldn't understand. God if this is the way that you made me, why is this such a bad thing?' Though performing a bold action by his bringing a boyfriend to church, Komplexity still posited his own identities against the dominant masculinities emphasized by family, showcasing an internalized struggle against these external influences present.

Beyond family, Queer Men of Color discussed their K-12 schooling experiences as influencing their masculinities. In addition to seeing masculinities tied to the ways that his father provided for his family who represented a 'strong man,' Benjamin mentioned that he also learned messages in high school. Specifically, he came out in high school, much to his peers' displeasure. He recalled how he was barraged with harmful words tied to femininity: 'Back then I understood them as the intention was hurtful.' Though brave in coming out initially, Benjamin internalized the notion that queer relationships were to be feared, emphasizing one way of being a man. Benjamin shared that he learned he was not 'thick-skinned,' which later influenced his decisions to come out to people and his fraternity. Like Benjamin, Derek talked about his time growing up in a small town:

I didn't really fit in and I didn't know myself because it was, it's a country town. So everybody drives big trucks. Really country, does all the, what's it called, go mudding and like off-roading and having those bonfires and speaking real country. 
As Derek explained, he was 'scared about trying new things' that did not fit the masculine images of people in his town. He went on to state that he was confident that when he went to college, he wanted to 'kind of be a new person, try these things because it's a new start.' Participants like Derek then entered college with these ideas grounded upon peers and family.

\section{Undergraduate chapter: reifying hegemony and experiencing dissonance}

Once Queer Men of Color joined their chapters, these individuals encountered hegemonic behaviors that reinforced previous constructions of masculinities; however, this also represented a time when they questioned external influences based on seeing more productive masculinities or where they further found issue with hegemonic behaviors. The men referenced examples of hazing, chapter voting meetings, and informal interactions with brothers that served as main influences. These contexts emphasized that masculinities were tied to heterosexuality and ideals of hegemonic masculinity, such as being aggressive or hypersexual (see Yeung et al., 2006).

To begin, the Queer Men of Color shared instances during their undergraduate education when they encountered hegemonic masculinity in the force of hazing or the histories behind hazing. Notably, none of the MGC fraternity members discussed hazing experiences they underwent during their undergraduate experience, though this is not to assert hazing was not part of their experience. Several of the NPHC men, however, described acts that they performed to prove their manliness like 'taking wood.' Taking wood refers to receiving paddling, typically with a wooden paddle, from members of the fraternity. In fact, Aaron, a member of Upsilon, spoke about when he was pledging, he would even volunteer to take wood. When asked why, Aaron responded that the act showed the following:

You know, I'm gonna take wood. You know, I'm not going to just take the wood that I get just because I'm like, gonna get it, but l'll take wood for other people. One, it's building the bond between me and my line brothers, but it's also showing the chapter I'm a lot more, I'm a lot rougher than you give me credit for. 
In this instance, Aaron communicated that it was not only expected to take wood, but that he actively did so in order to reinforce his manliness and the ways that his chapter perceived masculinities, indicative of external meaning making. Specifically, Aaron wanted to show the hyperaggression that is typical of hegemonic masculinity (Yeung et al., 2006). Other participants referenced similar ideas to Aaron's. Evan, also an Upsilon member, shared this when he said,

You're already coming in with one hand tied behind your back, you're coming in with a deficit...because you're gay. So what are you going to do to counteract that? And the harder you go in your process, the harder you get beat, you could kind of like lessen that disrespect.

Evan did not fit in with the masculine ideologies of his brothers, which motivated him to display more hegemonic masculine behaviors. Yet, this pattern of proving oneself in terms of hegemonic masculinity extended as people were voting on who was going to be part of a chapter.

Numerous participants within MGC and NPHC fraternities referenced how their chapters voted down flamboyant queer people in order to not become the 'gay chapter on campus.' As Derek, a member of Phi, described, 'They were worried about little things being too gay for other masculine guys to join. Because most masculine guys want to join a fraternity because it's a masculine thing.' Like Derek, participants like Aaron and Komplexity noticed brothers openly voting against queer people. In turn, some Queer Men of Color in the study themselves would implicate the masculinities of others in order to divert attention from their own. Jeff, a Black man in Upsilon, talked about how he himself voted down a flamboyant gay man:

... there was this one guy and he was extremely flamboyant... And I was like, what if this guy joined the chapter? Like that's going to be like a reputation, and I'm not sure we're ready to handle that. And I remember like his name came up for vote to join the chapter, and I was the first one to be like, 'Uh, I don't think he's our material ...' 
In response to this, one of Jeff's brothers who exhibited many hypermasculine behaviors actually questioned his logic, which caused Jeff to reconsider how ingrained he was in hegemonic masculinity. In that moment, Jeff said that he saw how his brother 'spoke up for this man,' which caused him to state the following: 'And I look like ... the homophobic problematic brother. And that was so eye opening for me.' By naming the trope of 'the homophobic problematic brother,' Jeff recognized that he had reproduced the behaviors present in his fraternity.

Moreover, Queer Men of Color described informal moments when they perceived their brothers perpetuating hegemonic masculinity ideals, oftentimes tied to heteronormativity. These settings led participants to question the relationship between masculinities and sexuality. For example, Valentino, a member of Phi, started to question why his brothers accepted him over others. As Valentino described, he once was told '"Oh, I'm happy that you're..." I'm never going to remember the exact wording lines now. But something along the lines of, "If you're going to be gay, you should be a man."' These comments created dissonance in Valentino's mind about the ways that he was conforming to masculine behaviors to be accepted. Like Valentino, Scott recalled the language that he would hear people share across various settings:

Yes, it would happen in chapter meetings, it would happen at step shows. Some of the verbiage that was used like when we would see brothers visiting campus is, 'Oh, they got a fruitcake in the chapter' or 'Oh, they brought... Tinkerbell to the, to the step show.'

Though Scott stated that he was not out to his Omicron brothers during his undergraduate years because he himself was still questioning his sexuality, he still questioned these comments, indicating that he got to a point where he 'was not going to back down.' He pushed back on this mindset by asking, 'How inclusive are we if willingly spewing this language, this very derogatory language from our mouths when talking about a fraternity brother of ours?' By getting to the point where he felt comfortable to name these behaviors, Scott stopped rejecting the singular view of masculinities that he had 
accepted growing up with family. This paired with productive displays of masculinities started to positively impact participants' constructions.

In fact, participants referenced what they perceived as more progressive expressions of masculinities in their chapters that showed how men could perform in ways that do not reify dominance. For example, Jeff shared a moment where he was present when a line brother's mom disclosed suicidal thoughts. Jeff noted that his brother did not follow the hypermasculine trope that men cannot show authentic emotion:

And he got off the phone. And just like bawled in our arms and that was like, to me, that was what healthy masculinity looked like in the sense of being able to be brothers and be vulnerable and support one another through that.

Though Jeff noticed plenty of examples of hegemonic masculinity in his organization including hypersexual chants, displays of homophobic attitudes toward potential members, or bragging about sexual conquests, moments like this opened up the possibilities of what masculinities could look like for himself. As Jeff mentioned, 'That's when I saw healthy masculinity at play in the organization, when we can be vulnerable with one another. We can love one another.' Others spoke about how they viewed similarly productive masculine behaviors. For example, Benjamin referenced a time when his chapter experienced a difficult year:

The way that we all approached it I think was as like we're as a family, we're family. We have to provide for our family. We have to be there for each other. And I think that that-that's really the biggest trait of masculinity that played out is that idea of taking responsibility, providing for the family and making things happen with what we have ...

Benjamin argued that his chapter enacted the notion of providing for a family in a way that was supportive and did not reify a hypermasculine position, having an influence on how he saw masculinities. This view of masculinities expressed through love and care rather than dominance shaped how people made meaning of masculinities through fraternities. 


\section{Post-college interactions with fraternities: internal constructions of masculinities}

After graduating, participants shared how their continued engagement with organizations showcased their new constructions of masculinities. Almost all participants, with the exceptions of Benjamin and Derek, remained formally tied to their organizations through alumni chapters, national conferences, or by serving as advisors for undergraduate chapters. Participants additionally did so through informal avenues such as social media groups. Regardless of how they remained connected to the organizations, participants noticed that hegemonic ideals were still revered. For many participants, they articulated how having the chance to be away from members of their undergraduate chapters challenged them to think differently about masculinities. Rather than simply accepting their fraternal culture or experiencing dissonance as a result of it, participants such as Valentino and Jeff maintained a masculine identity defined by themselves, resembling a more internal voice and construction (Baxter Magolda, 2009).

This resulted in Queer Men of Color avoiding individuals or spaces that furthered hegemonic ideologies. After he graduated, Valentino decided to no longer engage with brothers who were problematic. For example, at national conventions, Valentino only met up with those he saw similar to him: 'Which in essence, you can think, "Well, why would you do that?" I just don't have time... You know, I could not have that toxicity in my life.' In this action, Valentino surrounded himself with those that were not perpetuating the 'homophobic comments' that he saw during his time as an undergraduate. Similarly, Jeff mentioned that he did 'not have the energy' to deal with the hypocrisy of men disparaging queerness while sexually engaging with men on the down-low, which led to him separating from the organization more.

In contrast to Valentino and Jeff, August took a different approach. August mentioned that he was involved with his undergraduate chapter after he graduated. When asked about what conversations he had with these men, August commented, 'I guess when it comes to the established like masculinity. Masculinity doesn't have to be inconsiderate. Like to be masculine doesn't mean that you get to say whatever you want to say, you get to do whatever you want to do.' August went on to explain that he rejected the aspect of hegemonic 
masculinity where people 'put on a facade, like you're strong enough to do whatever you want.' For him, masculinities involved being considerate of people, including marginalized populations and more specifically queer people. His dedication to the organization resulted in him actively trying to push back on the actions reinforcing hegemonic masculinity through his local chapter, those that centered being strong, and by serving on the executive board for a graduate chapter. As a part of this role, August made sure that there 'had to be an established culture of respect for all people,' like 'women or men or sexuality or anything around it.' Though August and Valentino differed, their actions both represented a divestment from hegemonic masculinity.

Furthermore, several participants were involved with chapters as advisors where they could challenge hegemonic masculinity. Though Scott initially did not disclose his sexuality with members of an undergraduate chapter he advised, he eventually changed his approach:

So I was like, all right, you know, this is when I'm trying to work to be more of my authentic $100 \%$ self, I'm going to try and integrate more with these brothers, not only as their advisor, but mainly as their fraternity brother. And help them understand that I mean that there are different people out here who may want to join the organization.

In this excerpt, Scott's discussion of being authentic meant embracing a more internal way of representing himself and thinking about what it meant to be masculine as a Queer

Person of Color. Similarly, Jeff spoke about his advising of chapters where he performed masculinities in a way that was more congruent with queer culture: 'My vernacular was more free when I would be like, advising specifically in NPHC and MGC. So I would use like "Sis" a lot and "Gurl" a lot. You know, "shade" and "What's the T."' Furthermore, Jeff felt more apt to interrupt issues that he saw permeating fraternity and sorority life as a whole. As he stated, 'So ... when I would see like hypermasculinity specifically with IFC ... I had no problem calling out those nice young white men from the farms when their behavior was extremely problematic.' Examples of these problematic behaviors included wanting to host a women's swimsuit competition, as well as 
interrupting the general 'sexism or the homophobia were running rampant in the middle of good [college town].' In these instances, Jeff's approach varied differently from when he would engage in the very behaviors that he was now critiquing, representing a change in his meaning making around masculinities.

Similarly, participants noticed how connecting with other Queer Men of Color allowed them to challenge these norms. For example, Evan talked about how he and other queer brothers responded to a heterosexual brother posting on a fraternity Facebook page that queerness was destroying the Black community:

And so, you know, a lot of us who are in that same gender loving group were saying, well, you know, they have to understand that masculinity is a social construct. There's no clear definition of masculinity or femininity. It's things that society has established ... And so we just felt like their fragile and toxic masculinity was being threatened.

Different from his undergraduate experiences, Evan and his queer brothers made an intentional effort to try to interrupt hegemonic masculine behaviors in their spheres. As Evan noted, 'And so I feel like it took me distancing myself from the toxicity of some of those members of my fraternity.' Hence, Evan no longer performed actions grounded in hegemonic masculinity and that were often perpetuated by his fraternity. Like Evan, Komplexity stated that he has pointed out toxic ideologies with his Tau brothers on Facebook. Komplexity shared that he has made comments on public fraternal groups with his ultimate feeling being that 'Whatever their views about me is what they're going to be, but I just kind of drop the boulder in the water and let it settle wherever it may.' Because fraternal relationships were still meaningful to these participants, the ability to push back on problematic ideologies was indicative of a more internal meaning-making structure. Moreover, internal meaning making involves being able to see one's identities as complementary like gender expression and performance despite environmental influences such as toxic behaviors from other brothers saying they are not (Baxter Magolda, 2009). Ultimately, Komplexity and Evan's decisions underscore an internal confidence that comes with not being reliant on external perceptions of masculinities. 


\section{Discussion}

Findings from this constructivist grounded theory contribute to extant literature in higher education and particularly, how individuals make meaning of gender in this social constructionist perspective (Connell, 1995; Kimmel \& Messner, 2013). First, the insights offered by the participants revealed that different environments and relationships prior to college served as key influences to how they conceptualized masculinities, resembling more passive constructions (Foste $\&$ Davis, 2018). Like Harris and Harper (2015), we found that Queer Men of Color named family and peers/schooling as two significant contextual influences that shaped masculinities. These pre-collegiate contexts presented to these Queer Men of Color that embodying masculinities meant presenting strong, taking on the responsibility as a provider, and upholding heteronormative ideals. For the participants, these messages were intricately tied to their moving through the world as cisgender Men of Color. Even in Scott's situation where his family did not follow traditionally gendered scripts, he was still taught to associate Black masculinities with certain traits. Next, participants like Komplexity spoke about how masculinities were connected to family's belief in faith. Recognizing that scholarship has emphasized the unique relationships that Queer Students of Color have with religion (see Duran, 2019) better explains this finding. Though participants varied in the degree to which they performed outside of hegemonic masculinities, families and peers continued to serve as a significant influence for these individuals' meaning making as Men of Color. Specific to this study, the Queer Men of Color articulated how the messages they received about hegemonic masculinities were oftentimes connected to heteronormative expectations such as Komplexity's experience at church or Valentino's family inquiring about his girlfriend. Of note, their racial cultures shaped these expectations around gender and sexuality. It was these influences and norms with which Queer Men of Color entered their fraternal organizations.

In culturally-based fraternities, participants recognized hegemonic masculinity while also seeing the productive forms that masculinities can take, influencing their meaning-making in the process. In particular, participants began to push back on the messages they had previously internalized about hegemonic masculinity that taught them 
more inclusive masculinities or queerness was not congruent. As literature has shown, culturally-based fraternities can perpetuate negative ways of performing masculinities as Men of Color (e.g. Anderson et al., 2011; Jenkins, 2012). Supplementing these perspectives, Queer Men of Color shared examples of hazing, marginalizing comments made at chapter meetings, or homophobic attitudes that manifested. A unique contribution of this study was that it highlighted how these hegemonic masculinities served to marginalize queer individuals by making them prove their manliness in pledging, avoiding disclosing their sexuality for the sake of being accepted, and showing culturallybased fraternities as largely incongruent with openly queer members. These insights are significant for two main reasons. One, this research showed that this is the case from the perspectives of queer members themselves which is different from the literature using samples of heterosexual individuals to discuss cultures of masculinities (e.g. DeSantis \& Coleman, 2008). Two, this study focused how the manifestations of hegemonic masculinities extend to culturally-based fraternities, organizations founded to uplift Communities of Color (Torbenson, 2009). As Scott noted, these practices are counter to the inclusive nature of these groups. And still, it is important to note is that these hegemonic masculinity is not exclusive to culturally-based fraternities, as these behaviors emerged from larger issues of institutionalization in the academy (Mahoney, 2019) and are present across fraternity life (Biddix, 2016).

Additionally, as McGuire et al. (2020) showed, participants named how organizations exposed them to productive masculinities, those that are healthy and that lead to positive outcomes, which inherently shaped these men's perceptions of their queerness. Encountering both hegemonic and productive masculinities informed students' meaningmaking capacities. Specifically, students started to question the external reliance on masculinities without being at a place to completely internally construct views on masculinities for oneself. This is seen with members such as Jeff actively voting down openly gay men because of the internalized hegemonic masculinity and heteronormativity that he had. Yet, in being questioned by one of his fellow brothers, he critically reflected on what masculinities meant to him, especially as a Queer Man of Color. Thus, this moment of questioning external influences meant that Queer Men of Color wrestled with how their fraternal 
organizations constructed norms around gender and sexuality that they had potentially internalized.

Finally, a major contribution of this research concerns the fact that participants were alumni. Thus, these Queer Men of Color could speak about masculinities in relation to involvement beyond their undergraduate chapters. Though participants noted that they still perceived hegemonic masculinity permeating the organization in spaces such as conventions, the meaning-making process they engaged in now varied largely due to their distance from members of their undergraduate chapters, and reasonably, also due to a process of maturation. Specifically, the Queer Men of Color mentioned that they increasingly challenged the constructions of masculinities within their organizations, as seen in Evan and Komplexity doing so via Facebook. In these instances, participants were at a place where they saw identities as complementary, rather than succumbing to external influences teaching them that they should be at conflict with one another; these patterns resembled more complex meaning-making structures (Baxter Magolda, 2009). Consequently, participants saw their gender expression, sexuality, and race in a more positive light by not relying entirely on the beliefs that select peers or family taught them. Knowing that students may be faced with hegemonic and heteronormative discourses during their time in their culturally-based fraternities (e.g. DeSantis \& Coleman, 2008; Mahoney, 2019; Williams, 2017), it is imperative to know that Queer Men of Color can develop complex meaning-making structures in order to resist these ideologies once they graduate.

\section{Implications for future research and practice}

In examining the findings above, several directions for future research and practice emerge. Many of these directions stem from the limitations present in this own research. For instance, participants in this project did not largely discuss other intersections like class and ability in their interviews. Therefore, researchers can target these experiences in addition to expanding participant pools to include those who are in Native- and Asian/Asian American, Pacific Islander, and Desi Americanbased organizations as noted in our study design section. Similarly, 
our investigation of masculinities for Men of Color was severely limited given that there were no trans Men of Color in our sample. Additionally, few studies in higher education have investigated how Queer Women of Color negotiate their sexuality, gender, and racial identity (Duran, 2019). The literature that exists on this population suggests that Queer Women of Color navigate collegiate environments differentially based on their gender identity (e.g. Patton \& Simmons, 2008). Therefore, both scholars and practitioners would benefit from an increased understanding of the experiences of Queer Women of Color in settings such as culturally-based sororities. In addition to shifting the focus of identities, researchers could also interrogate how Queer Men of Color encounter similar or different challenges in historically white fraternal organizations. Finally, future research could mobilize critical and poststructural perspectives by using frameworks like queer of color critique or quare theory in the study of masculinities to investigate how systems of power are reified within culturally-based fraternities or how individuals perform identities in fluid ways.

For practitioners, the study's findings lead to changes in how professionals work with culturally-based fraternities, particularly on three levels: advisor relationships, fraternity and sorority life offices, and national FSL organizations. Of note, these recommendations can apply to all types of fraternal organizations, as these issues are present throughout FSL. To begin, participants largely did not recognize ways their advisors addressed hegemonic masculinities within their chapters; however, we contend that advisors can in fact play a crucial role in cultivating more productive cultures. To do so, advisors of culturallybased fraternal organizations must be cognizant of the ways that hegemonic masculinity permeates chapters on college campuses and ways that they as advisors may contribute to these behaviors. Therefore, in the same way that students may undergo trainings, advisors should also be required to attend trainings of hegemonic masculinity within FSL. Next, advisors should make a concerted effort to be present at meetings, as these were specific spaces where problematic behaviors appeared for many participants. Advisors could also have structured conversations with executive board and general members about how the chapter is informing their ideas about what it means to be a masculine person, challenging them on how they are making meaning of masculinities. 
Next, FSL offices at higher education institutions have a responsibility to create spaces for Men of Color to process matters of race, sexuality, and masculinities. For example, Valentino discussed how his campus hosted a 'Queer in Culturally-Based Fraternities' program series where students could learn about what it meant to be a sexual minority in these organizations from members. Additionally, August described how his university held an academic class for those wanting to join culturally-based fraternities. Hence, trainings around masculinities could be incorporated into classes or member education opportunities. By speaking to what initial constructions of masculinities people bring with them and how chapters are informing these ideas, FSL organizations can preempt the promulgation of problematic behaviors.

National organizations must also interrogate the ways that conversations within their fraternities are inherently grounded upon structures of heterosexism, hegemonic masculinity, and trans oppression. This change requires rethinking how policies, leadership, and practices can become more equitable when sexuality, gender, and race are taken into account. Participants mentioned that national fraternal organizations are a crucial site where hegemonic masculinity must be targeted. Hence, national organizations should make an intentional effort to have discussions about these issues at conventions, seeking out keynote speakers and presenters who can speak to these matters. National organizations should also partner with social justice consultants to perform trainings, survey members, and strategically plan about addressing topics of masculinities.

Finally, we contend that this manuscript can also be beneficial to heterosexual cisgender members of culturally-based fraternities to learn more about the experiences that queer brothers encounter in these organizations. It is imperative that in order to advance values of brotherhood, which many culturally-based fraternities profess, members reflect on who is included when constructing these bonds. If community only applies to those who perform hegemonic masculinity and who identify as straight, these groups fall short of their espoused commitments. Therefore, individual members in culturally-based fraternal organizations have the capacity to interrupt problematic behaviors and actions, especially for their queer brothers. 


\section{Conclusion}

As the topic of masculinities continues to gain attention in higher education and student affairs (see Catalano et al., 2018), practitioners, organizations, and members require nuanced perspectives on the intersecting identities that students hold and the contexts informing their constructions of masculinities. First, sorority and fraternity life campus professionals and chapter advisors will benefit from hearing these stories in order to construct more inclusive environments for Queer Men of Color in college. Second, leaders of culturally-based national organizations should learn how they can effect change as it relates to the cultures of gender and sexuality in their respective groups. Third, heterosexual members of culturallybased fraternities must gain a better understanding of how to support their queer brothers. What was unique about this study is that the findings showcased how hegemonic masculinity intertwined with how Queer Men of Color perceived the culture of heteronormativity in their culturally-based fraternities. Consequently, changes must continue to be made within these groups. It is when numerous levels-advisors, FSL offices, and national organizations-make an effort to have intentional conversations about masculinities that culturally-based fraternities could positively influence all members and especially Queer Men of Color.

\section{Notes}

1. See National APIDA Panhellenic Association (n.d.) for more information regarding the term Desi American.

\section{Contributors}

Antonio Duran (he/him), Ph.D. is an Assistant Professor in the Administration of Higher Education program at Auburn University. His research explores how historical and contemporary legacies of oppression influence college student development, experiences, and success.

Crystal E. Garcia (she/her), Ph.D., is an Assistant Professor in Educational Administration at the University of Nebraska-Lincoln. Her research critically examines the mechanisms by which racially minoritized college students experience campus environments. 


\section{References}

Anderson, E. (2008). Inclusive masculinity in a fraternal setting. Men and Masculinities, 10 (5), 604-620.

Anderson, R., Buckley, P. M., \& Tindall, N. T. J. (2011). Black Greek-letter fraternities and masculinities. In M. W. Hughes \& G. S. Parks (Eds.), Black Greek-letter organizations 2.0: New directions in the study of African American fraternities and sororities (pp. 114-132). University Press of Mississippi.

Baxter Magolda, M. B. (2009). The activity of meaning making: A holistic perspective on college student development. Journal of College Student Development, 50 (6), 621-639.

Biddix, J. P. (2016). Moving beyond alcohol: A review of other issues associated with fraternity membership with implications for practice and research. Journal of College Student Development, 57 (7), 793-809.

Catalano, D. C. J., Wagner, R. \& Davis, T. (2018). Approaching masculinities through a gender-aware practice framework. In D. C. J. Catalano, R. Wagner, \& T. Davis (Eds.), Gender-aware practices: Intersectional approaches to applying masculinities in student affairs. New Directions for Student Services (no. 164, pp. 11-17). San Francisco: Jossey-Bass.

Chan, J. (2017). "Am I masculine enough?": Queer Filipino college men and masculinity. Journal of Student Affairs Research and Practice, 54 (1), 82-94.

Charmaz, K. (2014). Constructing grounded theory (2nd ed.). London: Sage.

Connell, R. W. (1987). Gender and power: Society, the person and sexual politics. Sydney: Allen \& Unwin.

Connell, R. W. (1995). Masculinities. Berkeley: University of California Press.

Creswell, J. W., \& Poth, C. N. (2018). Qualitative inquiry \& research design: Choosing among five approaches (4th ed.). Thousand Oaks, CA: Sage.

Dancy, T. E. II. (2011). Colleges in the making of manhood and masculinity: Gendered perspectives on African American males. Gender and Education, 23 (4), 477-495.

DeSantis, A. D., \& Coleman, M. (2008). Not on my line: Attitudes about homosexuality in Black fraternities. In G. Parks (Ed.), Black Greek-letter organizations in the twenty-first century (pp. 291-312). Lexington, KY: The University Press of Kentucky.

Duran, A. (2019). Queer and of color: A systematic literature review on Queer Students of Color in higher education scholarship. Journal of Diversity in Higher Education, 12 (4), 390-400.

Edwards, K. E., \& Jones, S. R. (2009). "Putting my man face on": A grounded theory of college men's gender identity development. Journal of College Student Development, 50 (2), 210-228.

Foste, Z., \& Davis, T. L. (2018). "Am I doing this right?": A qualitative exploration of how college men make meaning of gendered expectations. Men and Masculinities, 21 (5), 583-602. 
Harris, F. III. (2010). College men's meanings of masculinities and contextual influences: Toward a conceptual model. Journal of College Student Development, 51 (3), 297-318.

Harris, F., III., \& Harper, S. R. (2014). Beyond bad behaving brothers: Productive performances of masculinities among college fraternity men. International Journal of Qualitative Studies in Education, 27 (6), 703-723.

Harris, F., III., \& Harper, S. R. (2015). Matriculating masculinity: Understanding undergraduate men's precollege gender socialization. Journal of the First-Year Experience \& Students in Transition, 27 (2), 49-65.

Hughes, B. A. (2017). The influence of masculinity on self-authorship (Doctoral dissertation). Retrieved from https://vtechworks.lib.vt.edu/

Jenkins, R. D. (2012). Black fraternal organizations: Understanding the development of hegemonic masculinity and sexuality. Journal of African American Studies, 16 (2), 226-235.

Jones, S. R., Torres, V., \& Arminio, J. (2014). Negotiating the complexities of qualitative research in higher education: Fundamental elements and issues (2nd ed.). Abingdon: Routledge.

Kegan, R. (1994). In over our heads: The mental demands of modern life. Cambridge, MA: Harvard University Press.

Kimmel, M. S., \& Messner, M. A. (2013). Men's lives (9th ed.). Boston: Pearson.

Mahoney, A. D. (2019). Queering Black Greek-lettered fraternities, masculinity and manhood: A queer of color critique of institutionality in higher education (Doctoral dissertation). Retrieved from University of Louisville Electronic Theses and Dissertation. (Paper 3286)

McGuire, K. M., McTier, T. S., Jr., Ikegwuonu, E., Sweet, J. D., \& Bryant-Scott, K. (2020). "Men doing life together": Black Christian fraternity men's embodiments of brotherhood. Men and Masculinities, 23 (3-4), 579-599.

National APIDA Panhellenic Association. (n.d.). NAPA name change affirms commitment to desi community. Retrieved from https://www.napahq.org/ napa-name-change-affirms-commitment-desi-community $/$

Patton, L. D., \& Simmons, S. L. (2008). Exploring complexities of multiple identities of lesbians in a Black college environment. The Negro Educational Review, 59 (3-4), 197-215.

Strayhorn, T. L., \& Tillman-Kelly, D. L. (2013). Queering masculinity: Manhood and Black gay men in college. Spectrum: A Journal on Black Men, 1 (2), 83-110.

Tillapaugh, D. (2013). Breaking down the "walls of a façade": The influence of compartmentalization on gay college males' meaning making. Culture, Society, \& Masculinities, 5 (2), 127-146.

Tillapaugh, D. (2015a). Critical influences on sexual minority college males' meaning-making of their multiple identities. Journal of Student Affairs Research and Practice, 52 (1), 64-75.

Tillapaugh, D. (2015b). "Writing our own rule book": Exploring the intersectionality of gay college men. In D. J. Davis, R. J. Brunn-Bevel, \& J. L. Olive (Eds.), Intersectionality in educational research (pp. 172-188). Sterling, VA: Stylus. 
Torbenson, C. L. (2009). From the beginning: A history of college fraternities and sororities. In C. L. Torbenson, \& G. Parks (Eds.), Brothers and sisters: Diversity in college fraternities and sororities (pp. 15-45). Madison, NJ: Fairleigh Dickinson University Press.

Williams, J. M. (2017). Ostracized insiders: Exploring the experiences of Black gay men in historically Black Greek letter fraternities (Doctoral dissertation). Retrieved from https://oaktrust.library.tamu.edu/

Yeung, K.-T., Stombler, M., \& Wharton, R. (2006). Making men in gay fraternities: Resisting and reproducing multiple dimensions of hegemonic masculinity. Gender \& Society, 20 (1), 5-31. 